\author{
$14^{\text {th }}$ Symposium on Nutri Indonesia \\ in conjunction with \\ $6^{\text {th }}$ International Nutrition Symposium \\ July 27-28, 2019 | Jakarta, Indonesia
}

\title{
ABSTRACT
}

\section{Correlation of Beta Carotene and Nutrition Status with Malondialdehyde Levels in Breastfeeding Mothers}

\author{
Katya Saphira, ${ }^{1}$ Nurul Ratna Mutu Manikam, ${ }^{1}$ Dwirini Retno Gunarti ${ }^{2}$ \\ Department of Nutrition, Faculty of Medicine, Universitas Indonesia, Cipto Mangunkusumo Hospital, Jakarta, Indonesia \\ 2. Department of Biochemistry and Molecular Biology, Faculty of Medicine, Universitas Indonesia, Indonesia
}

Link to DOI:

10.25220/WNJ.V03.i1.0011

Journal Website:

www.worldnutrijournal.org

Background: Malondialdehyde (MDA), one of the products of polyunsaturated fatty acid (PUFA) peroxidation detected in breast milk (BM). MDA levels depicted BM's oxidative status. BM oxidative balance could prevent oxidative stress in babies. MDA could be influenced by antioxidant food source such as beta carotene as well as body mass index (BMI). Objective: To analyze beta carotene intake and BMI and their correlation with BM MDA levels in nursing mother

Methods: Eighty breastfeeding mothers who were 20-40 years old, came to Cilincing and Grogol Petamburan Public Health Centre February-April 2019 and had 1-6 months old babies were enrolled in this cross-sectional study. The BM was extracted in the next day. Mothers were asked to empty one of the breast 2 hours prior to extraction. Beta carotene intake was assessed using semi quantitative food frequency (SQ-FFQ). Body weight and height was measured on the first day. The BM MDA levels were assessed using thiobarbituric acid reactive substance (TBARS) assay. The correlation of beta carotene intake and MDA as well as BMI and MDA was assessed using Spearman test with level of significance of $p<0.05$.

Results: Subject's median age was 27 (20-35) years old, median BMI was 23.21 (15.25-39.55) $\mathrm{kg} / \mathrm{m}^{2}$. Beta carotene's median intake was $8039.8(1697.7-34028) \mu \mathrm{g} /$ day with $72.5 \%$ of the subjects were considered to have low intake. BM MDA level's median was $1.953(0.739-4.928)$ $\mathrm{nmol} / \mathrm{ml}$. Beta carotene intake $(\mathrm{r}=0.247, \mathrm{p}=0.027)$ and $\mathrm{BMI}(\mathrm{r}=0.285, \mathrm{p}=0.010)$ had a weak correlation with BM MDA level.

Conclusion: The beta carotene intake and the BMI of the subjects correlate significantly with the BM MDA level. It showed that the mother's intake and body composition contribute to the oxidant level in BM, therefore influenced the level of oxidative stress transferred to the babies. Keyword: Breast milk, MDA, breastfeeding, beta carotene, babies

Corresponding author:

Katya Saphira

Jl. Janur Elok VI Blok QE 12 No. 8

Email address: katya.saphira@gmail.com 